\title{
Mechanical Properties of Rice Husk Fiiled Cashew Nut Shell Liquid Resin Composites
}

\author{
Michael Ikpi Ofem ${ }^{1}$, Muneer $\operatorname{Umar}^{1} \&$ Friday Aje Ovat ${ }^{2}$ \\ ${ }^{1}$ School of Materials, University of Manchester, Grosvenor Street, Manchester, UK \\ ${ }^{2}$ Department of Mechanical Engineering, Cross River University of Technogy, Calabar, Nigeria \\ Correspondence: Michael Ikpi Ofem, Room A3 Material Science Centre Building, School of Materials, \\ University of Manchester, Grosvenor Street, Manchester M17hs, UK. Tel: 44-161-306-2255, 44-755-031-0907. \\ E-Mail: Michaelofem@ymail.com
}

Received: May 4, 2012 Accepted: June 6, 2012 Online Published: September 17, 2012

doi:10.5539/jmsr.v1n4p89

URL: http://dx.doi.org/10.5539/jmsr.v1n4p89

\begin{abstract}
The need to have composite materials that are renewable has lead to materials scientists researching on natural fibres. To minimize environmental pollution research into rice husk has been on for a period of time now. In this research cashew nut resin reinforced rice husk composite was fabricated at different particle sizes and different filler loading. The present study reveals that both filler loading and particle size can affect the tensile strength, young modulus, strain at failure, flexural strength, and impact strength. As the $\%$ filler content increases all particle sizes $(400 \mu \mathrm{m}, 600 \mu \mathrm{m}$ and $800 \mu \mathrm{m})$ shows a quadratic relationship except \% elongation at failure which tends to be linear at $400 \mu \mathrm{m}$. As particle size increases all \% filler content shows quadratic relationship which tends to be linear. As particle sizes increases impact strength for 10 and $30 \%$ shows a linear equation while $20 \%$ shows a quadratic relationship which tends to be linear. In general, RH/CNSR composite could be considered as a potential source of low cost, natural fibre for composites.
\end{abstract}

Keywords: mechanical properties, filler loading, particle size, rice husk, cashew nut resin

\section{Introduction}

Material Scientists now focus on the use of natural materials for the development of composite materials. The attention is due to their renewable characteristics. To improve on the mechanical properties and obtain the desired characteristics that will be suitable for particular application different matrixes are used for reinforcing natural fillers at various particle sizes. Fillers having cellulose, hemi cellulose and lignin are being investigated for the suitability of replacing synthetic fibres. The use of these natural fillers has been due to its economic advantage during processing, high specific strength, relatively low density and the biodegrability, thereby reducing environmental pollution (Premalal, Ismail, \& Baharin, 2002; Bledzki \& Gassan, 1999). One lignocellulosic filler has been well investigated is rice husk.

Previous research into rice husk as fillers using various matrixes has been reported. Yang, Kim, Son, Park, Lee and Hwang (2004), and Prachayawarakorn and Yaemboonying (2004) reported on the effect of the mechanical properties of rice husk particle sizes, contents and crosshead speeds. The result shows that tensile modulus increases with increasing filler loadings while the composite becomes brittle at higher crosshead speeds. Mustapha, Hassan and Rahmat (2005), and Ismail and Suryadiansyah (2004) reported the successive utilization of rice husk, $\mathrm{CaCO}_{3}$, silica and black carbon as fillers while Zaini, Rowell and Sanadi (1995) reported that for all filler sizes, the mechanical properties of Polypropylene (PP)/kaolin composites decreased with increasing filler content. The incorporation of fly ash into PP matrix resulted into better tensile modulus, while the tensile strength, elongation at break and impact strength decreased with increasing filler loading (Nimityongskul \& Daladar, 1995; Ahmad, AbuBakar, \& Mokhilas, 2005; Stark \& Rowlands, 2003). A relationship between decreasing particles size and increasing impact strength in mineral-filled PP was also reported (Jiken, Malhmmar, \& Selden, 1991).

One of the problems associated with thermosetting polyesters and epoxy resins are pollution due to it nonbiodegradability and also some volatiles are given off in the course of its usage. Due to these disadvantages, the need to expand research on natural polyester resins seems applauding. One of such matrix is cashew nut resin. 
Cashew nut shell resin (CNSR) is a natural resin that can be obtained from cashew nut. Application of rice husk is found in particle boards, cement, chemicals and condensed silica fume (Satyanarayana, Ramos, \& Wypych, 2005) while CNSR applications is found in brake linings and clutch facings, surface coating and as anti corrosive (Lubi \& Thachil, 2000) Cashew nut is mostly found in Nsukka area of Enugu State Nigeria in commercial quantity. This paper therefore aimed at forming natural composites at different filler content using rice husk as filler while cashew nut shell resin is used as the matrix and to carry out studies of the resulting mechanical properties.

\section{Experimental}

\subsection{Materials}

Rice husk (RH) was supplied by local rice mill in Ugep Cross River State Nigeria. Cashew nut was obtained from Obollo-Afor cashew plantation in Udenu local government area of Enugu State Nigeria. All chemicals: saline solution constituents, catalyst (Methyl ethyl ketone peroxide (MEKP)), accelerator (Cobalt naphtha Nate (CDA-4301)), Poly vinyl acetate (PVA), wax and $\mathrm{NaOH}$ pellets used were all of commercial grade.

\subsection{Preparation of the Composite}

The composite was prepared by compression moulding technique after pre-treatment of the rice husk fillers, while cashew nut shell resin (CNSL) was extracted using the "hot-oil-bath" method as describe below. The cashew nut was broken into two halves to remove the edible part. The shells were poured in a vat pan containing n-hexane; it was allowed to stand for 24 hours, filter out the solution and then heated to distil of $n$-hexane leaving behind only CNSL. Oxalic acid and CNSL were mixed (ratio $1 \mathrm{~g}: 32 \mathrm{ml}$ ) in a three neck $500 \mathrm{ml}$ reactor equipped with stirrer and water cooled condenser. The solution was purge with nitrogen for 10 minutes and heated to $70^{\circ} \mathrm{C}$, formaldehyde was slowly added, heating continue for about 2 hours at this temperature and then increased to $150^{\circ} \mathrm{C}$ to remove water. What left behind is cardanol novolak resin. 1 mole of cardanol novolak, 1 mole of glycidylmethacrylate(GMA) and $0.8 \%$ of benzyltriethy ammonia chloride were mixed in a $500 \mathrm{ml}$ three neck reactor equipped with stirrer and water-cooled condenser, the mixture is purge with nitrogen for 10 minutes and heated to $105^{\circ} \mathrm{C}$, GMA was added and allowed to heat for about ten hours, a resin is obtained. Rice husk $(\mathrm{RH})$ was soaked in water to remove sand and other impurities, dried in the sun and later in an oven at $70^{\circ} \mathrm{C}$ overnight. The dried $\mathrm{RH}$ was treated with $3 \mathrm{~N} \mathrm{HCl}$ for 2 hours at a temperature of $80-90^{\circ} \mathrm{C}$ to remove low molecular weight hemicelluloses. $\mathrm{RH}$ treated $\mathrm{HCl}$ was washed in deionised water, dried in an oven and then immersed in hot $4 \mathrm{~N} \mathrm{NaOH}$ solution at $100^{\circ} \mathrm{C}$ for $2 \mathrm{~h}$ to remove silica and lignin, washed thoroughly with deionised water and then air dried. Different particulate sizes $(400 \mu \mathrm{m}, 600 \mu \mathrm{m}$ and 800$)$ of dry treated RH fibres were thoroughly mixed by mechanical stirring with CNSR at different filler content (10, 20 and 30\% by weight) for 30 minutes. CNSR was also cast without any filler. Prior to filling the mould with the resin matrix and the reinforcement, the inner surface of mould was coated with universal mould release wax to facilitate easy removal of the CNSR/RH composites. The mixture was then spread uniformly on the surface of the mould and hot pressed at $55^{\circ} \mathrm{C}$ for 30 minutes at a pressure range of 3-4 MPa. All the specimens were then post cured at $50^{\circ} \mathrm{C}$ for $12 \mathrm{~h}$ and machined into tensile, flexural and impact specimen shapes according to ASTM D 638M, ASTM D 790M and ASTM D 256M standard tests.

\subsection{Mechanical Testing}

Tensile strength, tensile modulus, flexural strength, \% elongation were measured using Universal Testing Machine - UTM (Instron 5567) while RAY-RAN Universal Pendulum Impact System for Izod-Charpy-Tension and Puncture was used for impact test. Tensile test specimen were made according to ASTM D 638M, while flexural strength test samples were made according to ASTM D 790M and impact strength test specimen were made according to ASTM D 256M. Five samples were tested for all filler contents and average results were used. A crosshead speed of $5 \mathrm{~mm} / \mathrm{min}$ was used. All specimens were conditioned at a temperature of $23 \pm 2{ }^{\circ} \mathrm{C}$ and $50 \pm 5 \%$ relative humidity for 48 hours before testing.

\section{Results and Discussion}

\subsection{Effect of\% Filler and Particle Sizes on Tensile Strength, Young Modulus and Strain at Failure}

The mechanical properties of a natural fibre composite depend on among other things on the orientation and distribution of the fibres or fillers, the matrix phases and the phase volume fractions. Figures 1 and 2 show the tensile strength versus \% filler content curves and tensile strength versus particle gauge size for cashew nut resin reinforced rice husk fillers respectively. Figure 1 shows that for each particle size there is a gradual increase in tensile strength as the filler content increases. The percentage increase drops from $116 \%$ at $0 \%$ filler content to $18 \%$ at $30 \%$ filler content, an indication that an increase in $\%$ filler content may not increase the tensile strength. 
This result is in contrast to earlier results (Yang et al., 2004; Ahmad et al, 2005; Ismail, Nizam, \& Abdul Khalil, 2001) but agrees with others (Raghu, Bose, \& Mahanwar, 2006; Ofem \& Umar, 2012; Sapuan, Harimi, \& Maleque, 2003). The gradual increase in tensile strength could be attributed to the strengthening between the interface of resin matrix and filler materials. This could only happen when there is proper miscibility between rice husk and the resin. The proper miscibility result into less voids and so better stress transfer. Another reason for the increase in tensile strength as filler loading increases is attributed to fibre treatment with $\mathrm{HCl}$ and $\mathrm{NaOH}$. Chemical treatment improves the adhesion between the filler and the matrix due to the removal of low molecular weight hemicelluloses, silica, lignin and other artificial impurities. The removal of these impurities results into rough surface topography and so better adhesion (Bisanda \& Ansell, 1991). A maximum tensile strength of 35.2 MPa was recorded at $30 \%$ filler and particle size of $400 \mu \mathrm{m}$. At any given $\%$ filler content, irrespective of the particle size the composites demonstrate quadratic behaviours. The quadratic relationships are shown in the graph (Figure 1) each has a correlation factor of 1.

Figure 2 show the infinitesimal particle gauge size curves. The curves follow the same quadratic behaviours as in Figure 1. Tensile strength decreases from about $10 \%$ at $400 \mu \mathrm{m}$ to $6 \%$ at $800 \mu \mathrm{m}$ when filler content is $10 \%$. At 20 and $30 \%$ filler contents the same trend with little variations in percentage decrease was observed. As the particle size increases, there is an increase in interfacial area, this increase in interfacial area result into poor interfacial bonding and inefficient stress transfer between filler and matrix polymer. The poor bonding result in decrease in the $\%$ increase in the mechanical properties. The quadratic relationship in Figure 2 indicates that a maximum tensile strength of $28.94 \mathrm{MPa}, 40 \mathrm{MPa}$ and $43.2 \mathrm{MPa}$ for 10, 20 and $30 \%$ filler content respectively will be obtained. From Figures 1 and 2, the best mechanical properties were obtained at $30 \%$ filler content and $400 \mu \mathrm{m}$.

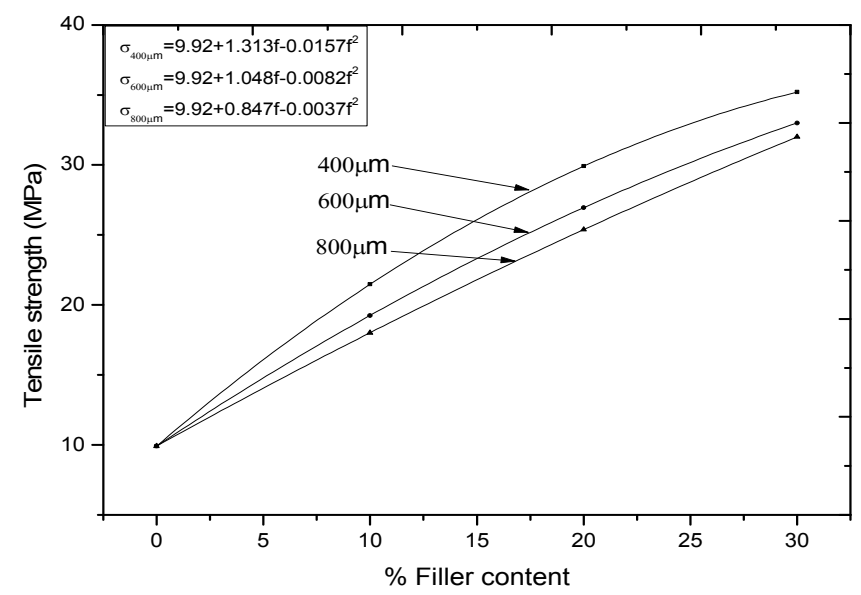

Figure 1. Tensile Strength vs. \% filler content of RH/CNSL Composite

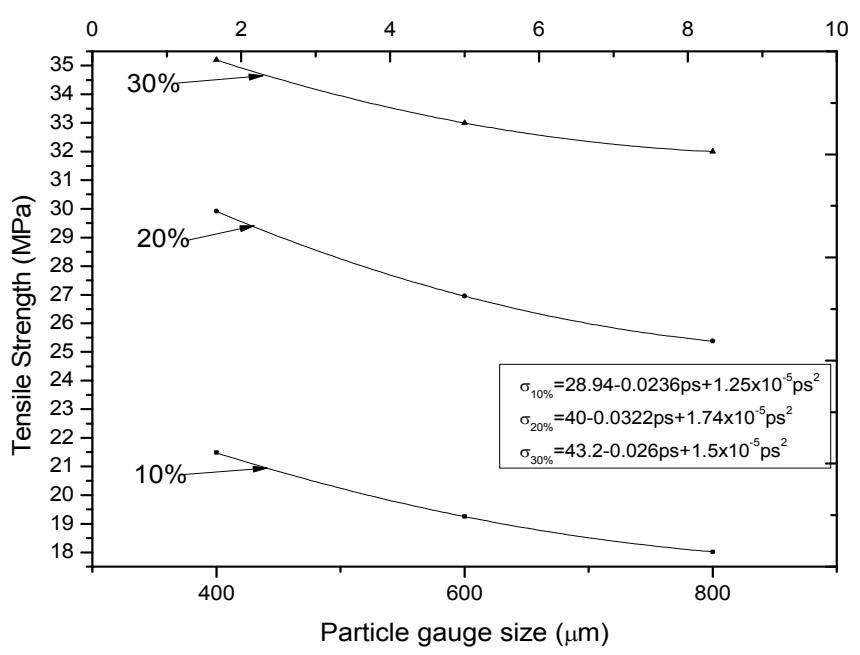

Figure 2. Tensile Strength vs. particle gauge size of RH/CNSL Composite 
Figures 3 and 4 show the tensile modulus versus \% filler content curves and tensile modulus versus particle gauge size. Like tensile strength Figure 3 show that for each particle size there is a gradual increase in tensile modulus as the filler content increases. The percentage increase drops from $83 \%$ at $0 \%$ filler content to $9 \%$ at $30 \%$ filler content. Similarly there is a gradual decrease in young modulus as the particle size increases. The $\%$ decrease between $400 \mu \mathrm{m}$ and $600 \mu \mathrm{m}$ is four times higher than the $\%$ decrease between $600 \mu \mathrm{m}$ and $800 \mu \mathrm{m}$. Again the issue of increase in interfacial area, when particle size increases game to play, resulting into poor interfacial bonding and inefficient stress transfer there by reducing the Young modulus. The increase in Young modulus as the filler content increases is an indication that rice husk has a greater stiffness than the matrix, in other words smaller particle size exhibit small aspect ratio and so appear to be less stiff. Earlier results (Ismail \& Suryadiansyah, 2004; Ahmad et al., 2005; Ofem \& Umar, 2012; Harimi \& Maleque, 2003) show a similar trend. Both the particle sizes and the \% filler contents show quadratic relationships as shown in Figures 3 and 4 with corresponding correlation factors of 1 .

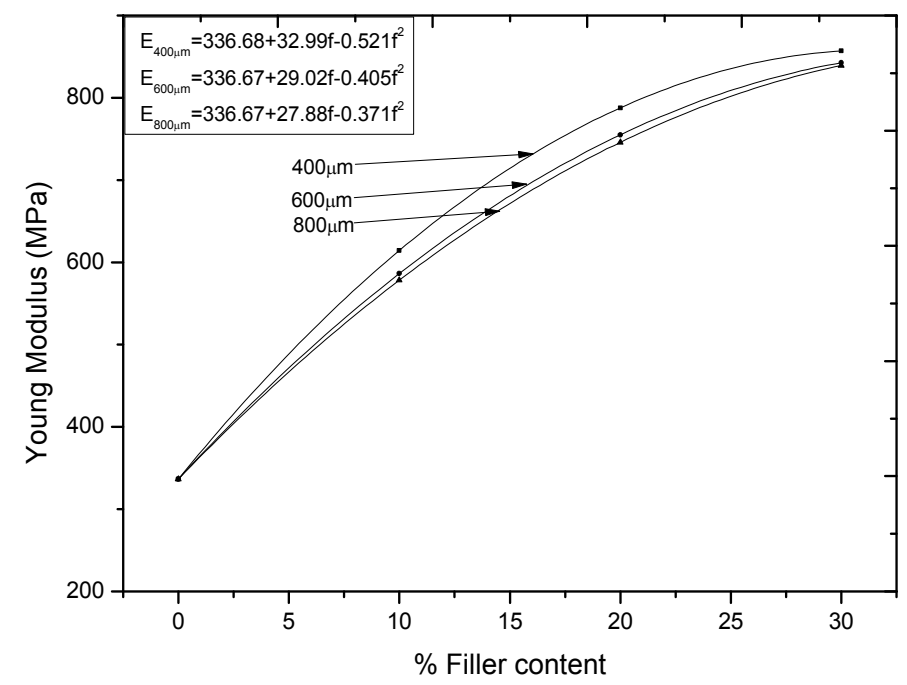

Figure 3. Tensile Modulus vs. \% filler content of RH/CNSL Composite

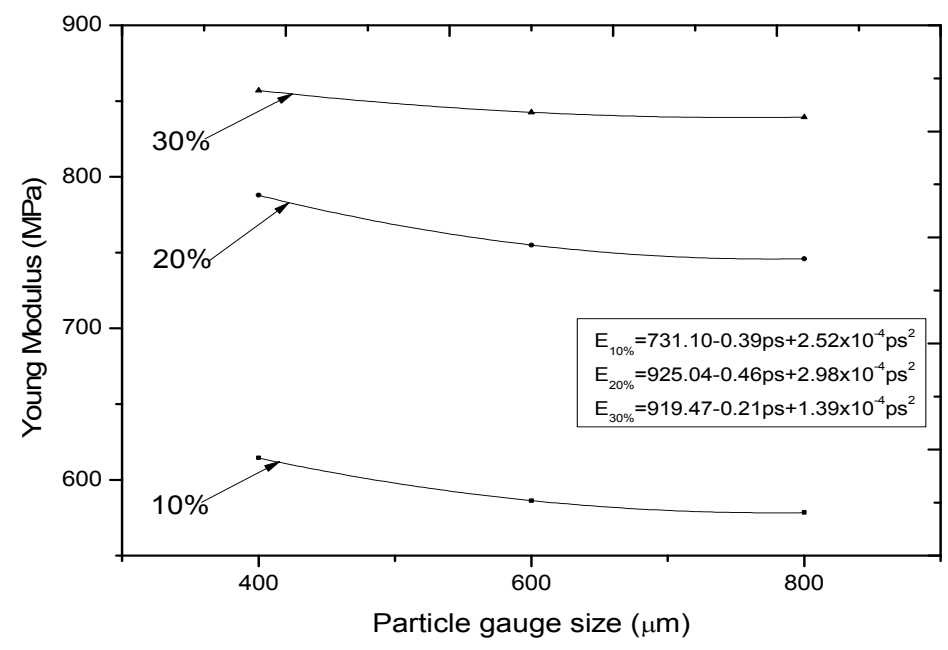

Figure 4. Tensile Modulus vs. particle gauge size of RH/CNSL Composite

Figure 5 shows that tensile strain increase as \% filler increases. This is contrary to other result (Ismail \& Suryadiansyah, 2004; Raghu, et al., 2006; Sapuan et al., 2003). Ahmed et al. (2005) got two diverse results in his work "recycled pet for rice husk/polyester composites." The fibre treated composite exhibited increase in strain as the filler loading increases while the untreated composite exhibit the reverse. In their work (Sapuan et al., 
2003) when a compatibilizer of Poly-(propylene-ethylene-acrylic acid) was added to the composite the tensile strain increases as the filler loading increases. This is an indication that treatment of the fibres can lead into increase in tensile strain as the filler loading increases. In this work there was proper treatment of the fibre with first $\mathrm{HCl}$ and later $\mathrm{NaOH}$. This treatment may have reduced the hindrance of molecular mobility or deformation resulting into increase in tensile strain as the filler loading increases. There was a marginal percentage drop in tensile strain $(10-13 \%)$ as the filler content increases at $400 \mu \mathrm{m}$ particle size but remain constant $(10 \%)$ at $600 \mu \mathrm{m}$ and varies $(5-9 \%)$ at $800 \mu \mathrm{m}$. The uniformity in percentage drop as the filler content increases could be attributed to equal distribution of fillers in the matrix, absence of void, homogeneity of matrix and uniformity of filler sizes. Figure 6 shows the infinitesimal particle gauge size curves. Except for $400 \mu \mathrm{m}$ particle size which tends to be in a linear relationship, $600 \mu \mathrm{m}$ and $800 \mu \mathrm{m}$ show a quadratic relationship as the filler content increases. As the particle sizes increases the tensile strain at failure tends to be linear. The equations of relationship are shown in the curves. All equations show correlation factor of 0.99 .

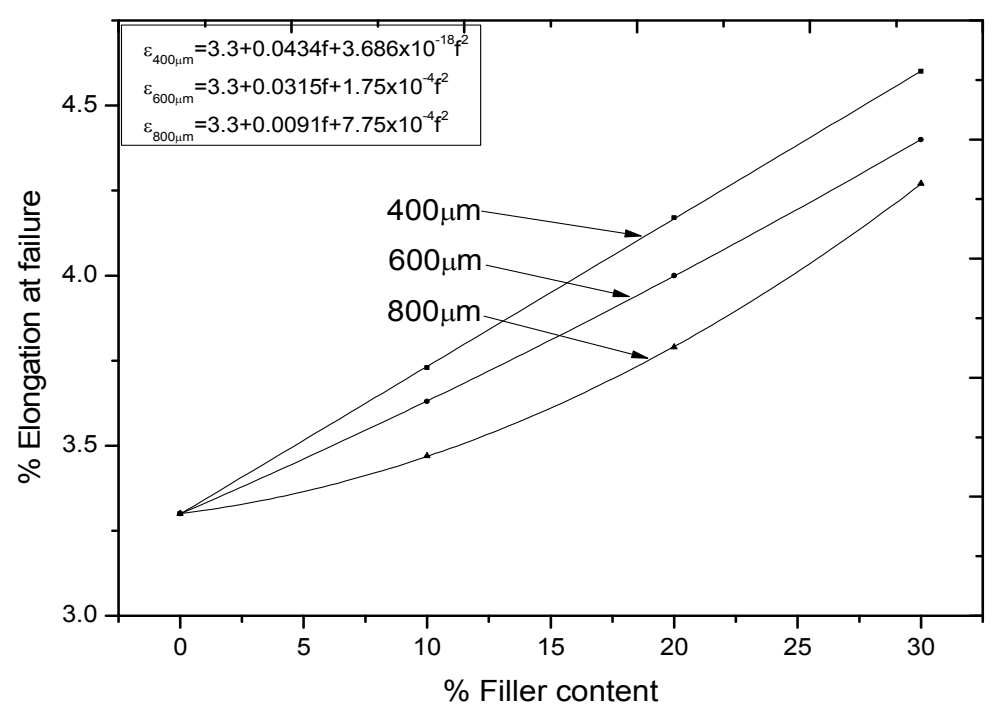

Figure $5 \%$ Elongation at failure vs. \% filler content of RH/CNSL Composite

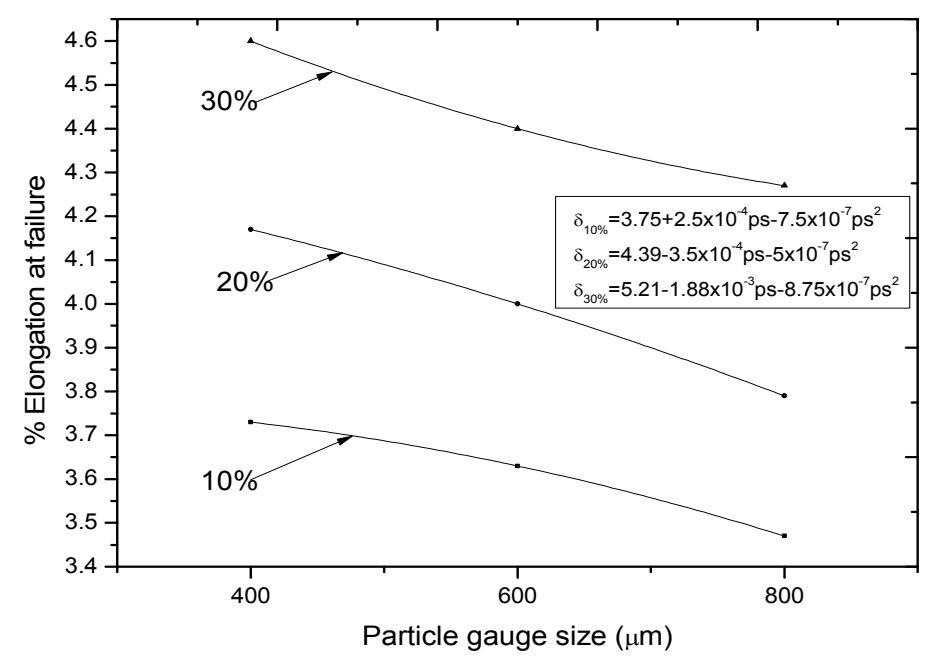

Figure $6 \%$ Elongation at failure vs. particle gauge size of RH/CNSL Composite

\subsection{Effect of \% Filler and Particle Sizes on Flexural Strength}

Figures 7 and 8 show the variations in flexural strength and the infinitesimal particle gauge size curves of the composites with different filler loadings. It is observed that flexural strength increases gradually with increase in filler loading for all the particle sizes. A close observation indicates that the rate of increase in flexural strength 
remains almost the same for various filler loadings. Irrespective of the filler loading and the particle size the percentage increase is between 20 and 24. As particle size and filler loading increases there is a reduction in total surface area available for matrix filler interaction resulting into increase in mobility of matrix molecules and the reverse is the case at lower filler loading and particle size because of the increase in surface area. The increase in filler content results in almost linear increase as shown in Figures 7 and 8 with a correlation factor of 1 for $400 \mu \mathrm{m}$ and $600 \mu \mathrm{m}$ and 0.99 for $800 \mu \mathrm{m}$.

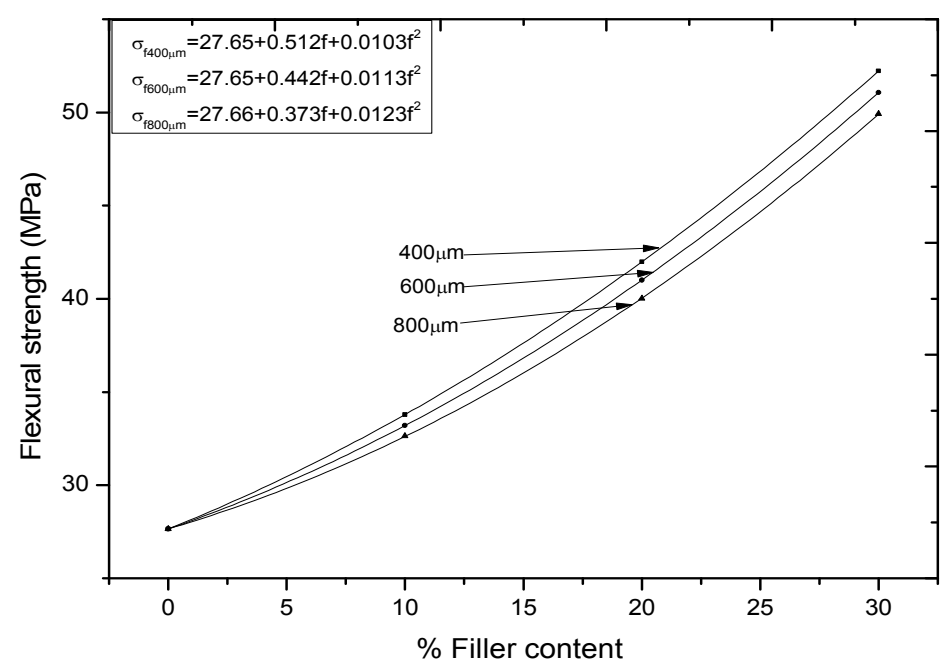

Figure 7. Flexural Strength vs. \% filler content of RH/CNSL Composite

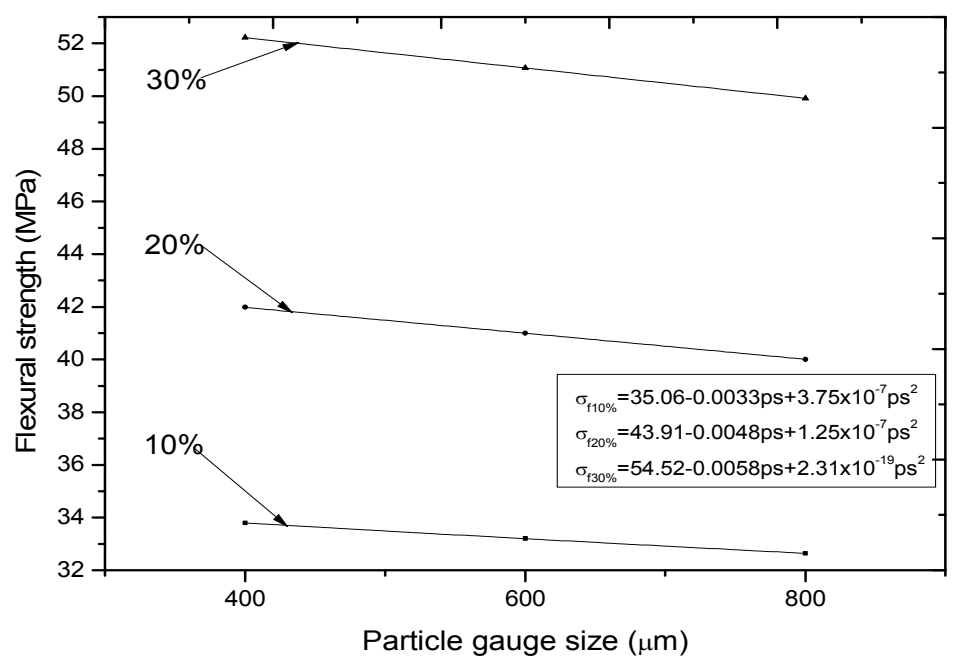

Figure 8. Flexural Strength vs. particle gauge size of RH/CNSL Composite

\subsection{Effect of \% Filler and Particle Sizes on Impact Strength}

Impact strength is the ability of a material to withstand shock loading or the ability of a material to absorb mechanical energy in the process of deformation and fracture under impact loading. Crack propagation is initiated in a composite material when it is subjected to impact loading. Presence of longitudinal fibres at the loading points contributes to increase in resistance to crack propagation and invariably better mechanical properties. This can only take place if the interfacial adhesion between the matrix and the longitudinal filler is strong enough to with stand the impact loading. Poor Interfacial adhesion between the matrix and the filler will result into a crack, lowering the impact strength of the composite. As particle size and filler loading increases 
there is a reduction in total surface area available for matrix-filler interaction resulting into increase in mobility of matrix molecules. Due to the increase of mobility of matrix molecule the particle sizes tends to accumulate, increase in accumulation result into weakening of the interfacial adhesion between the matrix and the filler. It is there for expected that as the filler content and particle size increases there will be a decrease in impact strength. Be that the case the development of new chemical, for surface treatment and dispersion of fillers in the polymer has resulted into better mechanical properties including impact by adding filler according to Bisanda and Ansell, 1991. Figures 9 and 10 shows the variations in impact strength and the infinitesimal particle gauge size curves of the composites with different filler loadings. In all cases the impact strength increases as the filler loading and particle sizes increases. The percentage increases reduces as the particle size and filler loading increases. The increase could be attributed to surface treatment of the fillers prior to the formation of the composite. While figure 9 shows quadratic relationship as the filler loading increases, Figure 10 show linear relationship for 10 and $30 \%$ filler content and quadratic relationship for $20 \%$ filler loading as the particle size increases. The equations of relationships are shown in the graphs. A correlation factor of 0.99 for all particle sizes was observed.

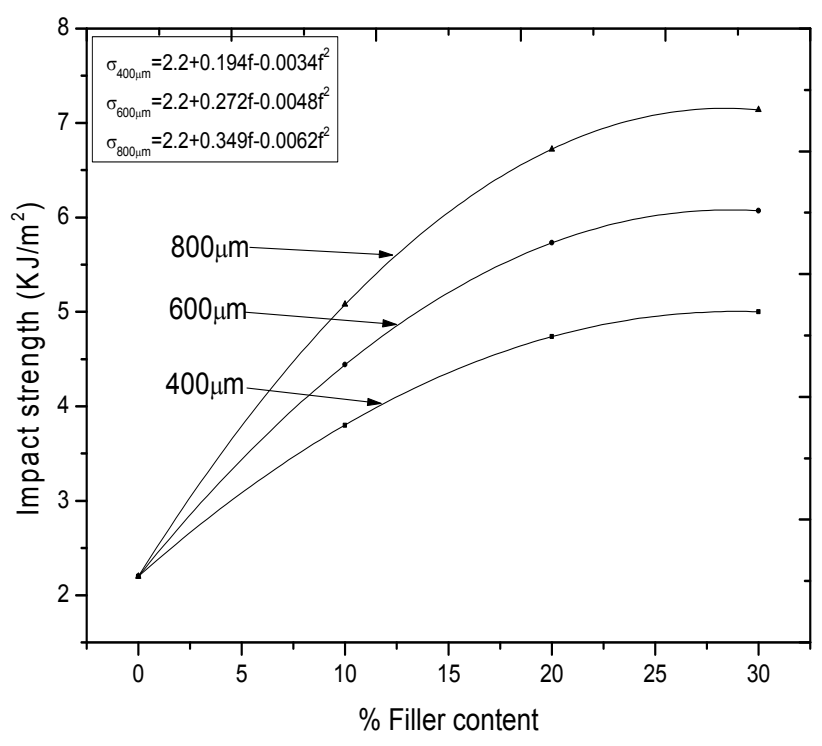

Figure 9. Impact Strength vs. \% filler content of RH/CNSL Composite

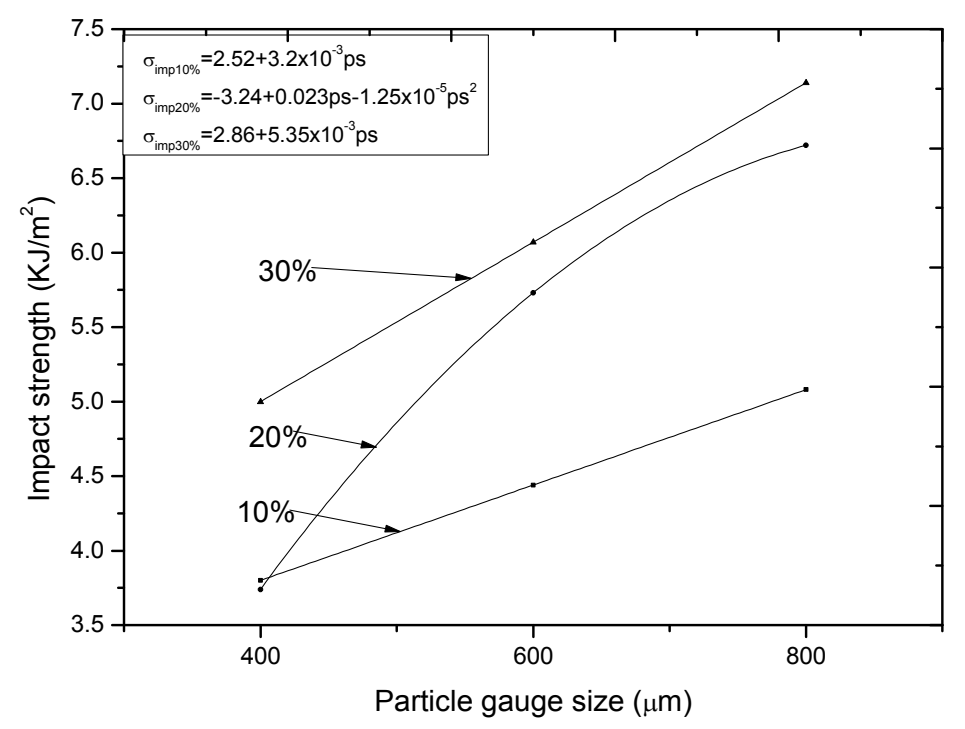

Figure 10. Impact Strength vs. particle gauge size of RH/CNSL Composite 


\section{Conclusion}

The effect of rice husk filler loading and particle size on the mechanical properties of as-prepared composite have been studied. The result shows that better mechanical properties were obtained as the filler loading increases but decreases as the particle sizes increases except for impact, the strength increases as the particle sizes increases. Also both filler loading and particle sizes show a quadratic relationship with a correlation factor of between 0.99 and 1. As the particle size increase both 10 and 30\% filler loading shows a linear relationship while $20 \%$ filler loading shows a quadratic relationship which tends towards linearity.

\section{References}

Ahmad, I., AbuBakar, D. R., \& Mokhilas, S. N. (2005). Recycled PET for Rice Husk/Polyester Composites. Asian Journal for Science and Technology Development, 22(4), 345-353.

Bisanda, E. T., \& Ansell, M. (1991). The effect of saline treatment on the mechanical and physical properties of sisal-epoxy composites. Composite Science and Technology, 41, 165-178 http://dx.doi.org/10.1016/0266-3538(91)90026-L

Bledzki, A. K., \& Gassan, J. (1999). Composite reinforced with cellulose based fibres. Prog. Poly. Sci., 24(2), 221-274. http://dx.doi.org/10.1016/S0079-6700(98)00018-5

Yang, H. S., Kim, H. J., Son, J., Park, H. J., Lee, B. J., \& Hwang, T. S. (2004). Rice-husk flour filled polypropylene composites; mechanical and morphological study. Composite Structures, 63, 305-312. http://dx.doi.org/10.1016/S0263-8223(03)00179-X

Ismail, H., \& Suryadiansyah, A. (2004). Effects of Filler Loading on Properties of Polypropylene-Natural Rubber-Recycle Rubber Powder (PP-NR-RRP) Composites. Journal of Reinforced Plastics and Composites, 23(6), 639-650. http://dx.doi.org/10.1177/0731684404032869

Ismail, H., Nizam, J. M., \& Abdul Khalil, H. P. S. (2001). The effect of a compatibilizer on the mechanical properties and mass swell of white rice husk ash filled natural rubber/linear low density polyethylene blends. Polymer Testing, 20, 125-133. http://dx.doi.org/10.1016/S0142-9418(00)00013-1

Jiken, L., Malhmmar, G., \& Selden, R. (1991). The effect of mineral fillers on impact and tensile properties of polypropylene. Polymer Testing, 10, 329-344. http://dx.doi.org/10.1016/0142-9418(91)90011-L

Lubi, Mary C., \& Eby, Thomas Thachil. (2000). Cashew nut shell liquid (CNSL)-a versatile monomer for polymer synthesis. Designed Monomers and Polymers, 3(2), 123-153. http://dx.doi.org/10.1163/156855500300142834

Mustapha, M. S. E., Hassan, A., \& Rahmat, A. R. (2005). Preliminary study on the mechanical properties of polypropylene rice husk composites. Simposium Polimer Kebangsaan Ke-V Hotel Residence, 23-24: 185-191. Retrieved from http://eprints.utm.my/3267/1/L14_spk05_fp_Mohd_Shahril.pdf

Nimityongskul, P., \& Daladar, T. U. (1995). Use of coconut husk ash, corn cob ash and peanut shell ash as cement replacement. Journal of Ferrocement, 25(1), 35-44.

Ofem, M. I., \& Muneer, U. (2012). Effect of filler content on the mechanical properties of periwinkle shell reinforced CNSL resin composites. ARPN Journal of Engineering and Applied Sciences, 7(2), 212-215.

Prachayawarakorn, J., \& Yaemboonying, P. (2004). Mechanical and morphological properties of rice husk-filled polypropylene. Chiang Mai J of Science, 31(1), 35-44. Retrieved from http://www.adhesion.org/admin/paper/114SCI029.pdf

Premalal, H. G. B., Ismail, H., \& Baharin, A. (2002). Comparison of the mechanical properties of rice husk powder filled polypropylene composites with talc filled polypropylene composites. Polymer Testing, 21, 833-839. http://dx.doi.org/10.1016/S0142-9418(02)00018-1

Raghu, H., Bose, S., \& Mahanwar, P. A. (2006). Effect of Particle Size of Filler on Coloration and Properties of High Density Polyethylene. Journal of Mineral and Materials characteristics and Engineering, 5(1), $87-100$.

Sapuan, S. M., Harimi, M., \& Maleque, M. A. (2003). Mechanical properties of epoxy/coconut shell filler particle composites. The Arabian Journal for Science and Engineering, 28(2B), 171-181. Retrieved from http://ajse.kfupm.edu.sa/articles/282B_04P.pdf 
Satyanarayana, K. G., Ramos, L. P., \& Wypych, F. (2005). Development of new materials based on agro and industrial wastes towards ecofriendly society (pp. 583-624). Ghosh TN, Chakrabarti T, Tripathi G. (Eds.). Biotechnology in energy management. New Delhi: APH Publishing Corporation.

Stark, N. M., \& Rowlands, R. E. (2003). Effects of Wood Fibre Characteristics on Mechanical Properties of Wood/Polypropylene Composites. Wood and Fibre Science, 35(2), 167-174.

Zaini, R. E. Rowell, S. M., \& Sanadi, A. R. (1995). Recent developments in annual growth lignocellulosic as reinforcing fillers in thermoplastics. Proceeding of 2nd Biomass Conference of the Americas: Energy, Environment, Agriculture and Industry, 1171-1180. 